\title{
Dealing with the three facets of uncertainty in planning: evidences from a processual study on basic education in Rwanda
}

DOI: http://dx.doi.org/10.4314/rj.v3i1.2B

M. Kamuzinzi, University of Rwanda

\begin{abstract}
Since the emergence of management as a science in the early years of the twentieth century, the concept of planning is naturally associated with rational anticipation of future course of actions. Critical theories showed that this ideal type of planning is rarely functional in real the world as complex organizations' future behaviors are hardly predictable. But their critiques pointed out in different directions, offering the impression that the purposes of planning are contradictory and irreconcilable. Champions of incrementalism conceptualize planning as a process of small sized adjustments to new pieces of information. Contingent theorists conceive planning as an adaptation to environmental change and complexity. Communicative theorists foresee planning as a consensus-building in a context of divergent interests. Action theorists go far and envisage planning as a symbolic rationalization of previous choices and, finally the resourcedependence theorists figure planning as a legitimating strategy aiming at increasing credibility and attracting external resources. This article posits that there is a common ground to these apparently contradictory theoretical perspectives, since they attempt to tackle three facets of uncertainty in planning: environmental, political and financial uncertainty. Furthermore, it conceptualizes different dimensions each of the three types of uncertainty could take in real planning and investigates them through an in-depth processual study on basic education in Rwanda.
\end{abstract}

Key concepts: basic education, planning, uncertainty, Rwanda

\section{Introduction}

Classical authors did not envisaged the act of planning out of its traditional function of anticipating future course of actions (see for example Andrew 1971; Ansoff 1965; Learned \&al 1965; Steiner 1969). Most of their writings were guided by a rational model where the concept of planning is closely related to that of prediction. At theoretical level, this means-end planning process consists in establishing an imagined valued end or state of affairs and then set actions aiming at achieving this desired future (Kaplan, 1976).

In other words, planners guided by this ideal type are supposed to predict different courses of actions with their probable consequences and, compare each alternative with an imagined goal in order to choose the best option (Polkinghorne 1988). In Polkinghorne's perspective, this type of rationality follows the logic of the practical syllogism and, is teleological in that the validity of the conclusion is determined by the judgment of which events will produce consequences closest to the desired end. Consequently, the valid answer to the pragmatic question "What should be done?" is which course of activity is most likely to produce the desired future state of affairs 
(Polkinghorne, 1988, p.138). But, due to the low predictability of planning parameters in complex organizations, this ideal type of planning induced sharp critiques from different theoretical perspectives.

The first critique raised by Simon (1955) pointed out the human limited capacity to collect and process new pieces of information. This new insight opened the way to questioning the validity of rationalist theory when applied to complex decision-making processes. Simon's work inspired that of Lindbloom $(1959,1968)$ and Braybrooke \& Lindbloom (1963) on complex and politically motivated decisions. Their main conclusion was that politically motivated decisions are more characterized by "disjointed incrementalism" than by instrumental rationality. These authors showed that decision-makers act in a remedial than in rational way and, readjust continuously their targets as new changes occur.

Twenty years later, Quinn (1980) took a less radical position and showed that complex decision-making processes are guided by "logical incrementalism", where actors adjust progressively their decisions and actions according to new information received. Instead of being fully rational, Quinn (1982) suggested that complex decision-making process move forward by small sized adjustments in order to include new elements gleaned in different forums.

Critiques from the contingent theory focused on complex organizations incapacity to anticipate environmental changes. Authors like McCaskey (1974) or Mintzberg (1990, 1994) showed that planning intervening in simple and, stable environments offers the possibility of behaving rationally and choosing the best option in due time but, this cannot be done in complex and dynamic environments.

At empirical level, the study of Fredrickson (1984) supports this theoretical position. This author observed a positive correlation in the use of rational planning and the performance of organizations working in stable environments. A second study conducted in collaboration with one of his colleagues showed that there is no benefit to using rational planning in a dynamic environment (Fredrickson et Mitchell 1984). Five years later these authors decided to validate their results and conducted a more comprehensive study, which led to the same conclusions and confirmed previous results (Fredrickson \& Iaquinto. 1989). For contingent theorists, especially Mintzberg (1994), there is no benefit in engaging in rational planning when environmental factors change at a high pace.

Adopting a more political view of the act of planning, communicative theorists criticized the rational model of planning with regard to its incapacity to deal with conflicting group interests (Innes 1995, 1996, 1998; Innes \& Booher 1999; Sotarauta, 1998; Willson 2001; Willson \& al, 2003). For example, Throgmorton (1996) showed that planning intervening in a context of divergent interests, even technically valid data are interpreted differently by interested parties. Each actor or group of actors select strategically pieces of findings that support its interests and ignore those supporting others' benefits. 
With regard to the divergence of groups' interests, action theorists like Brunsson (1982, 1985) and, Starbuck (1983) formulated a more radical critique to the classical model of planning. For these authors, when group interests are irreconcilable, reaching a consensual choice may not be possible. In such circumstances, deciders operate secretly their choice and, engage afterwards in a symbolic participative planning. This stratagem aims at legitimating this privileged choice and let it appear as if it had been decided consensually by all stakeholders.

Resource dependence theorists (Stone \& Brush, 1996) showed that the rational model can be adopted for other purposes that are very far from its traditional function of anticipating future course of actions. For these authors, the rational model can be mobilized to legitimize the plan in the face of potential funders than to guide real choices (Llewellyn \& Tappin, 2003). This happens when planners are in shortage of internal resources and have not a clear idea of what external institutions will likely be interested in providing the need funds. Thus, the ideal type of rational planning can be adopted to increase the credibility of the organization and to reinforce its chance to attract external support rather than to anticipate future course of actions (Mintzerg \& Waters, 1982).

The above critiques of the rational model of planning raise the impression that existing theories did not focus on the same variables and hence, that empirical findings underlain by different theoretical frameworks are not comparable. This article posits that there is a common ground to their apparently contradictory assumptions, since they attempt to tackle three facets of uncertainty in planning: environmental, political and financial uncertainty.

\section{Conceptualizing the different facets of uncertainty within one "synthesis model"}

As stated in the introduction, existing theories displays apparently disjointed views on the purposes of planning. But, a careful analysis shows that all attempt to cope with the different facets of uncertainty that could hamper the implementation of the plan.

By proposing small sized adjustments instead of unrealistic long range projections, incrementalism and contingent theory attempt to moderate environmental uncertainty. The communicative and action theories attempt to cool political uncertainty by trying to temper actors' ardor in a conflicting choices. Resource dependence theory tries to decrease financial uncertainty by aligning the planning process to external demands.

In this new analysis model, we consider that these three dimensions of uncertainty are not mutually exclusive and that planners can face simultaneously all of them within the same planning process. Thus, there is no reason of conceiving existing theories as opposed conceptions of the act of planning. Instead, they should be considered as alternative strategies used by planners to cope with the multidimensional nature of uncertainty. In this model, we consider that the level of predictability or unpredictability of these three dimensions determine planners' behaviors in real planning. 
As far as environmental uncertainty is concerned, planners could face four types of planning scenarios:

- $\quad$ Setting future course of actions can be based on few and stable internal and external environmental indicators. In this case, the projection of future actions will be relatively easy. Their predictability will be facilitated both by the low number and the stability of variables to be considered in real planning. It is only in this rare scenario that planners could apply the ideal type of rational planning in their real work (Mintzberg 1990).

- Defining forthcoming actions can be based on few internal and external variables that change frequently. The unpredictability of future course of actions will be induced by the high rate of change and a bit dampened down by the low number of variables to be considered in real planning. As stated by Mintzberg (1990), this second scenario could incline planners to rely on incremental adjustments to adapt the planning process to these frequent changes.

- $\quad$ The projection of future actions can be based on complex and stable environmental variables. In this case, the unpredictability of future actions will be induced by the high number of parameters to be considered in real planning, but their stability constitutes a moderating factor. In Mintzberg's framework, this scenario lead to participative planning.

- $\quad$ The projection of future actions can be based on complex and changing environmental parameters. This last scenario represents the most challenging environment in planning. Unpredictability will be induced both by the high number of variables to be considered in the analysis and, by their frequent change. In this context, planners will likely prospect continuously different ways of moving forwards without being able to choose definitely the best option (Mintzberg 1994). In McCaskey's framework, this scenario is equivalent to planning without goals (McCaskey, 1974).

As far as the political dimension of uncertainty is concerned, planners could face three scenarios in real planning:

Planners could face actors with relatively homogenous interests. Thus, reaching a consensual option will be relatively easy. In this scenario, planners will likely rely on technical analysis to choose the best option as in the ideal type of rational planning.

- $\quad$ Planners could face actors with conflicting but negotiable interests, where reaching a consensual option is possible in due time. In this scenario, planners will likely rely on communicative planning (see Willson 2001; Willson \& al, 2003);

Planners could face actors with irreconcilable interests. Hence, reaching a consensual option could not be possible in due time. In this highly conflicting scenario, planners will possibly choose secretly their favored option and engage in symbolic participative planning as in action theory (see Brunsson, 1985; Starbuck, 1983). 
With regard to the financial dimension of uncertainty, planners could face three planning scenarios:

- $\quad$ In the first scenario, planners could project to use internal resources and, strategize to have the planned activities included in the ordinary budget of the organization. In this case, financial predictability is high and, planners will concentrate on technical justification of requested funds.

- In the second scenario, financing the projected activities could depend on one dominant external funder (Pfeffer \& Salancik, 2003). In this scenario, financial unpredictability will depend on the level of concordance or discordance of planners' desires and funder's exigencies. If there is no discrepancy between planners' wish and funder's conditionality, the financial uncertainty will be low. On the contrary, if planners are obliged to change their favored option in order to cope with funder's demands, the financial uncertainty will be high.

- $\quad$ In the third scenario, the planning process could depend on different external funders which have conflicting exigencies. In this scenario, planners will attempt to satisfy some actors and ignore others, in which case they may lose support from the neglected ones (Pfeffer \& Salancik, 2003). Another strategy could consist in relying on different arguments when legitimizing their option to different audiences (see Kamuzinzi, 2007; Kamuzinzi \& al, 2009a, b).

In sum, the conceptualization of existing theories as alternative strategies used by planners to cope with the different facets of uncertainty allows researchers to investigate these dimensions in the same study. In the following section, we illustrate how the above theoretical scenarios were investigated through a processual case study on educational planning in Rwanda.

\section{Methodology}

This study was conducted in Rwanda. It covered the period from July 1994 just after the genocide to July 2015, corresponding to the end period of the Education Sector Strategic Plan 2010-2015. The analysis focused mainly on aspects related education for all. In Rwanda, this last concept refers to free basic education. Before 2000, free education was limited to six years of primary education. Since 2007, free education was extended to nine years, including six years of primary and three years of secondary education. In 2012, free education was extended to twelve years, including de facto six years of primary and six years of secondary education.

The research was guided by the principles of a processual analysis (see Van de Ven \& Poole , 1990; Dawson,1997; Orton, 1997; Pettigrew, 1997; Ropo, Erickson \& Hunt, 1997). The adoption of this approach intended to identity and document methodically key changes that occurred in educational planning during this period in Rwanda. Two important sources of information were investigated: planning archives and interviews with key actors who participated in their elaboration. 
Analyzed archives included mainly the different version of educational plans produced from July 1994 to July 2015. Additional documents from the archives were also considered. Apart from being clearly related to an identifiable plan, each document had to fulfill at least one of the following criteria:

(1) Containing excerpts stating clearly the purpose of the plan considered and its expected outcomes;

(2) Containing excerpts describing environmental factors that impacted on the preparation or the implementation of the plan;

(3) Containing excerpts highlighting dominant internal actors' interests during the preparation or the implementation of the plan;

(4) Containing excerpts stressing external actors' exigencies or expectations during the elaboration of the plan.

Six versions of educational plans produced during these periods were identified (see Ministry of Education, 1998, 2003a, 2003b, 2007, 2008, 2010). Three additional documents were selected according to the above criteria and added to this sample. Interviews involved ten educational planners, ten representatives of churches and ten representatives of parents' associations owning schools who were involved actively in educational planning activities during this period. The analysis of archives and interviews focused on the different facets of uncertainty faced by planners and on strategies put in place to cope with these uncertainties at different periods.

The interpretation of findings consisted mostly in confronting key findings to the different scenarios of planning highlighted in the analysis model. From one plan to another, we identified internal and external factors that affected the planning process and rendered the situation more predictable or unpredictable for planners; actors' interests and subsequent strategies used by planners to reach a consensus on key issues and; finally external actors' demands that impacted on the planning process.

\section{Findings and discussion}

A careful "processual" analysis of archived plans and related documents highlights three important phases with very different characteristics: the first phase covers the emergency period from 1994 to 1998. During this phase, educational planners were "snowed under" with urgent matters, with little possibility to anticipate rationally what could be done in near future. Thus, this period could be qualified as a phase where planners "acted without a formal plan".

The second phase covers the period from 1998 to 2007, characterized by the alignment of educational plans to external context and a sort of disjunction between formal plans and real action. On one hand, educational plans produced during this period were mostly aligned on international trends without any significant adaptation to internal context. For example, long terms targets defined in the Dakar Declaration on education for all became de facto national references in formal plans as if the country was evolving in stable environment. On the other hand, real actions on the ground were 
characterized by small sized incremental adjustments to respond to much exceptionality induced by the post-genocide context.

The last phase covers the period from 2008 to 2015, characterized by the alignment of educational plans to internal context. During this period, we observe a shift from an "outsider" towards an "insider" planning perspective. For example, targeted outputs retained in the Educational Sector Strategic plans 2008-2012 and in the following versions are more realistic and aligned to internal budgets, from which annual performance indicators are selected and effectively implemented.

Why educational planners adopted different postures during these three phases? What types of uncertainty did they face during the three phases? How did they cope with the three dimensions of uncertainty discussed in the analysis model? Key findings on each phase are discussed in the same subsection in order to have an overview of its dominant characteristics and to identify key changes from one phase to another.

\subsection{Planning during the emergency period (1994-1998)}

The first dimension of uncertainty in our analysis model is related to environmental parameters. This facet was investigated through the analysis of internal context under which planners were operating. Furthermore, external environment influences were scrutinized. As far as the internal context is concerned, the analysis of planning archives showed that after the genocide in July 1994, educational infrastructures were totally destroyed; thousands of pupils and teachers had died or fled the country. During the following three years, the main focus was to repair and furnish destroyed classes with new desks, laboratories and offices and, to recruit new pupils and teachers. In certain regions, the teaching staff was totally renewed and more than a half of new pupils recruited.

One former planner interviewed summarized their working conditions during this crucial period as follow:

"During this period, we worked without any clear objective and no formal plan guided our initiatives. Whenever we got a support, wherever it came from and, whatever it could be, it was warmly welcomed and, used to solve the most imminent problems on hand."

In addition to this internal turmoil, a lot of pressures come from the external environment. Just after the genocide in July 1994, former refugees who fled the country in the sixties, returned back after more than three decades in exile with thousands of pupils seeking to continue their studies. Some of these pupils spoke English, others French, while the Rwandan educational system taught in Kinyarwanda in at least in primary schools. The educational system was so instable that planners faced always unplanned cases that needed exceptional decisions and urgent solutions. One representative of schools owners summed-up how they dealt with diversified pressures from external environment as follow:

"Every day we faced new problems and received diversified demands that had nothing common with existing standards. During this 
period, we were submerged by urgent meetings dedicated to such atypical issues. If we did not agree on how to tackle the problem, an ad-hoc committee was put on place to find a solution".

With regard to the different scenarios highlighted in the analysis model, this atypical context corresponds to the fourth scenario of environmental uncertainty. Planners faced many internal and external variables that in addition changed frequently. Thus, the unpredictability of future course of actions was very high. They had no other option than prospecting continuously ad-hoc solutions.

As far as internal actors' interests are concerned, the post-genocide atmosphere was so tragic that for parents, what mattered was to have places in the educational system for their children, whatever it could offer. At the beginning, some schools taught the national program while others taught foreign curricula! Others schools that had both a high number of French or English speaking pupils created parallel classes that taught different programs in different languages! On interviewed planner summarized this atypical context in these terms: "The context under which we operated was exceptional. This period was characterized by a lack of shared standards. Everything was discussed, even the curricula were negotiated".

Even if these temporary arrangements were potentially full of clashes, groups' interests were kept silent or negotiated. As all Rwandans were struggling to recover from the tragedy and, to find jobs in order to survive, their expectations on quality education were minimized. During this period, priorities were negotiated at all levels.

With regard to political uncertainty, this context corresponds to the second scenario of the analysis model, where planners face negotiable conflicting interests. Consequently, they relied on communicative planning principles as suggested by Willson \& al (2003) and were opened to diversified demands from different audiences.

Financial uncertainty was surprisingly low, even though the Rwandan educational system depended totally on external financial aid during this period. In the emergency period, planners faced few preconditions to access external funds. This context was described as follow by one interviewed planner:

"During the emergency period, access to external resources was not really subjected to constraining conditionality. The problem was that financial aid was dispersed and, managed by thousands of nongovernmental organizations which had different agendas. As we did not know who could respond positively to our concern, the same demands were addressed simultaneously to different organizations. A the end, there was someone who was ready to help!"

This empirical situation has no corresponding scenario in our analysis model. Planners were totally dependent to external funds but yet, they did not face tough preconditions to access these resources. This could be explained by the atypical context under which planners were operating 
during this period. As the international community was mobilized to support Rwanda, funds came from diversified sources. Thus, planners did not face shortage of funds, even though they had no internal resources.

This emergency period where planners acted without a formal plan lasted from July1994 to July 1998. The first attempt to develop a formal plan came later in the second semester of 1998. From 1998 to 2007, planners adopted a new logic consisting in aligning national plans to international conventions.

\subsection{Bringing national priorities into alignment with international trends (1998-2007)}

From 1998, the internal context became progressively stable. Refugees and internally displaced populations' movements had significantly reduced. Only few returnees came sparingly from bordering countries with a small number of pupils seeking places in the educational system. It is in that context that the first post-genocide educational plan was launched in the second semester of 1998 (Ministry of Education, 1998).

With regard to the external context, this period was mainly characterized by a strong renewal of international commitment to achieve the objectives of education for all defined a decade ago at Jomtien in Thailand (UNESCO, 1990). This framework was revisited in the Dakar Declaration in March 2000 (UNESCO, 2000). To seize these opportunities, one strategy adopted by Rwandan planners consisted in aligning national educational targets with internationally legitimated trends. For example, the objectives retained in the educational plan (1998-2000) were very similar to international targets defined in the Jomtien framework despite the fact that Rwanda was emerging from a very destructive genocide. The same similarities can be observed between the objectives retained in the educational plan for all (2003-2015) and the international targets defined in the Dakar declaration.

As far as actors' interests are concerned, this period was still characterized by consensual building as in the previous period. The educational system continued to adapt itself to diversified demands from different audiences. After 1998, consensus building evolved towards openness to diverse types of schools including public popular school, public elitist schools, churches and parents' owned schools, highly expensive schools teaching international programs, etc. Till now, Rwanda is among the African Countries that have a wide range of teaching programs originating from different educational systems.

As for the influence of external demands, this study showed that plans produced from 1998 to 2007 were mostly underlain by the need to convince international financial institutions that Rwanda is sharing the same vision and is committed to act on the basis of the same international conventions. The rational model of planning was mobilized most likely to produce a credible plan in the face of donors than to project effectively what was to be done in the future. 
This is for example the case for the Recovery and Development Education Plan (1998-2000) (Ministry of Education, 1998). This plan was designed on the basis of a rational model popularized by UNESCO experts in education sector (see UNESCO, 1983 a, b, c, d, e; Haddad \& Demisky, 1995). It was very detailed, with a diagnosis highlighting clearly the status of the educational system at the time and, the expected changes to be induced by the plan after the three years. But, surprisingly, this well designed document was not really used as a guiding document by implementers. Their work was still dominated by ad-hoc initiatives that had no link with the formal plan. Why planners did took time to write such a well designed document that was not really used in real work? The response came from a well experienced planner who worked in the ministry of education during this period:

"After three years, funders started insisting on the necessity of having a rational plan that should channel the diversified initiatives for which we were seeking money. Experts from UNESCO helped us to design this first plan. If, I interpret this initiative retrospectively, I think that the elaboration of that plan intended to convince donors that we had a vision, that we knew where we can from and what we intended to achieve in the future. But really, the internal context was still unpredictable and our work was still dominated by ad-hoc issues."

The alignment of educational plans with international conventions is more obvious in the plans produced from 2000 to 2007. Since 2000, two international trends dominated the debate on education for all in developing countries. The first tendency inspired by the Jomtien framework and reinvigorated by the Dakar Declaration focused mostly on the necessity of making basic education free of charges for parents. This tendency adopted a social stance promoting the idea that basic education is a fundamental right for all children, including those from very poor families, marginalized minorities and those living with disability.

In order to cope with this internationally legitimated convention, planners initiated a planning process that ended with the production of the educational plan for all (2003-215) that was fully aligned on the Dakar framework. Its objectives, the aspects covered and, even the deadlines of the implementation of each objective were all inspired by this international convention. This alignment can be captured from the minister's foreword presenting the plan to stakeholders:

"The plan is based on internationally established targets and indicators. The Dakar Framework for Action (2000) declared that by 2015, all children of primary school age would participate in free schooling of acceptable quality and that gender disparities in schooling would be eliminated; levels of Adult Illiteracy would be halved, and learning opportunities for youth and adults would be greatly increased; all aspects of education quality would be improved. This EFA Plan will assist us in our efforts to achieve these international EFA targets, for the benefit of all Rwandans" (Ministry of Education, 2003a, p. 4). 
The second trend was inspired by the international commitment to reduce poverty in developing countries. This tendency favored a more economic stance insisting mostly on the rationalization of resources allocated to the implementation of educational plans. As far as education for all is concerned, this new move was expressed in the "Fast Track Initiative Strategy" coordinated by the World Bank. In order join this initiative, planners were required to produce a rational plan showing clearly how education sector will contribute to the implementation of the Economic Development and Poverty Reduction Strategy (EDRSP).

To cope with this new international trend, Rwandan planners initiated a parallel educational planning process that ended with the publication of another version totally modeled on the "Fast Track Initiative" framework. Its alignment with this new framework can be easily captured from this quotation:

"The publication of the Education Sector Strategic Plan (ESSP) 2003-2008 is an important milestone towards developing Rwanda's education Sector. This forwards-looking plan, based on declared targets and indicators is an instrument to make the Education Sector Policy operational and is designed to assist in reducing poverty within Rwanda while creating a foundation for our vision of economic development based upon application of development skills and technology" (Ministry of Education, 2003b, p. 5).

Since 2004, this second perspective gained in popularity when multilateral and bilateral cooperation agencies started using the same framework to channel their financial support to implement the Economic Development and Poverty Reduction Strategy (EDPRS). In this perspective, education sector was considered as a component of this strategy as it appears in the Education Sector strategic Plan 2007-2011.

"This forward-looking plan is an instrument to make education sector policies operational and fully incorporates the government aims of reducing poverty and creating a foundation for economic development" (Ministry of Education, 2007, p. ii).

Planners brought their activities into alignment with this new framework in order to make their plan endorsed by donors. As many countries were competing to joint this international initiative, aligning the plan to the "Fast Track Initiative" was necessary in order to access external funds. Among key conditions to joint this initiative was the development of a Long Term Strategy and Financial Framework (LTSFF) channeling all public policies towards poverty reduction and, the design of rational educational plan showing clearly how it will contribute to the implementation of this long term economic strategy. After many attempts, Rwanda satisfied these conditions in 2006 and joined the "Fast Track Initiative" in 2007. As it appears in this quotation, bringing Rwandan educational priorities into alignment with this new framework was a determining factor to access external funds: 
"The ESSP is derived from the 10 year Long Term Strategy and Financial Framework (LTSFF). The LTSFF was endorsed by development partners in 2006 and contributed to the education sector in Rwanda qualifying for Fast Track Initiative (FTI) funding" (Ministry of Education, 2007, ii).

When asked why they decided to bring educational planning process fully in line with international trends while the national context was still instable and needed incremental small adjustments, one planner responded as follow:

"Well, in this globalized world, countries have come to share everything. Even educational planning frameworks are shared nowadays. Thus, if we chose to remain close to our internal context and did not behave as planners from others countries did, we could have lost the opportunity to join the Fast Track Initiative".

As far as the financial uncertainty is concerned, this empirical situation corresponds to the second scenario described in the analysis model. Even if the implementation of the educational plan depended on the contribution of diversified cooperation agencies, the reference to a shared framework put Rwandan planners in a position of dependence to one dominant external actor. But once, planners succeeded in securing donors support through the endorsement of the educational plan, relying on externally legitimated model lost its strategic character.

\subsection{From an "outsider" towards an "insider" planning perspective (2008-20015)}

The planning process started changing progressively from an "outsider" towards an "insider" perspective in 2008. Since planners had accessed the coveted external resources for which they strategized for a decade, mobilizing internal actors' ownership of the plan became a priority.

With regard to the internal context, Rwanda had fully recovered its political stability during this period. Consequently, many public institutions evolved towards more bureaucratization and standardization of work. As far as the educational system is concerned, this move towards standardization resulted in the definition of a shared national qualification framework. Regulatory agencies were put on place to set standards guiding the elaboration of teaching programs at all levels of the educational system. These include the Rwanda Education Board (REB) for nursery, primary and secondary schools and the National Council for Higher Education (NCHE) in charge of defining standards for higher institutions.

With these regulatory mechanisms on place, pressures from external environment did not disturb significantly the functioning of the education system as it was when planners worked without strong standards. In addition, joining the "Fast Track Initiative" increased future actions predictability as access to external funds reduced uncertainty. When confronted to the different scenarios of the analysis model, these findings show that after 2008, planners worked in a relatively stable environment corresponding to the first scenario in Mintzberg's contingent planning framework. 
The same could be said on the third dimension of the analysis model. With the internal resources allocation now predictable through the Long Term Strategy and Financial Framework and the external support now secured through the endorsement of the plan by the "First Track Initiative", planners were able to figure out the magnitude of future course of actions. Consequently targets defined in the Education Sector Strategic Plan 20082012 were more realistic and accurate. Educational needs were defined in terms of numbers of classes to be constructed, number of desks to be purchased, number of teachers to recruited, number of book to be printed each year, etc. (see Ministry of Education, 2008, 19-20). One interviewed planner described the context under which they worked after 2008 as follow:

"After we had joined the World Bank fast track initiative, setting realistic objectives for free basic education was relatively easy. We were now better informed about external resources we could count on. It was easy to identify covered and uncovered needs and, thus to mobilize additional means in order to achieve nine years basic education and later one twelve years basic education in due time".

What about the influence of internal actors' interests? The radical changes induced by this new plan raised a hot debate inside the educational system. Burning issues included the fixation of the allowed repetition rate at $10 \%$ maximum, the reduction of the number of courses to be taught at primary and secondary school, the introduction of the double shifting and the "specialization" of teachers. All these measures were introduced to reduce the cost of free education, but as internal actors contested them strongly, planners attempted to legitimize them using more acceptable arguments.

For example, the decision from the ministry of education to fix the rate of repetition at $10 \%$ maximum was taken in response to the critique from World Bank experts that the Rwandan educational system consumed more resources than needed because the repetition rate was very high. As traditionally, the Rwandan educational system was very selective, this measure raised strong disagreements from internal actors, especially from teachers and parents from the elite. They considered this measure as a sort of promotion of mediocrity. Planners made sense of it by referring to more acceptable arguments such as ": "a high repetition rate discourages students"; "an unnecessary repetition rate increases students' dropout"; "a superfluous repetition rate overloads teachers because it increases the number of pupils per class" or "a high repetition rate consumes places of the following cohort".

The decision to reduce the number of courses to be taught in primary and secondary schools was also legitimated as a way of increasing the quality of education while its real aim was to reduce the number of teaching hours and subsequently, the number of news teachers to be recruited. It was projected that a reduction from 9 to 6 subjects in lower primary will decrease teaching hours from 27 to 21 hours and, a reduction from 11 to 6 subjects in upper primary will diminish teaching hours from 31 to 21 . The introduction of double shifting and the specialization of teachers were also adopted for the 
same reasons but legitimated differently in order to moderate internal contestation (see Ministry of Education, 2008b, p.3).

Furthermore, the ministry of education also allowed a certain level of flexibility in the application of these measures. In order to reduce the contestation from the elite, privates and public boarding schools were allowed to increase teaching hours by subject, to add new subjects on the timetable and, even to change the repetition rate according the performance of students.

With regard to the analysis model, this study showed that decisions on the above controversial issues were taken using the principles of action theory (See Brunsson, 1985; Starbuck, 1983). Real choices were made before the formalization of the decision making process involving symbolically a wide range of stakeholders. Such decisions were legitimized afterwards using more pedagogically acceptable arguments.

\section{Conclusion}

The results obtained show that from one period to another, planners faced different kind of uncertainties. With regard to environmental uncertainty, the study showed that during the emergency period, planners faced highly dynamic and complex environment parameters. But these parameters evolved towards more stability, a context that allowed the ministry of education to set progressively regulatory mechanisms and standards shared by all schools.

With regard to political uncertainty, key findings show that during the emergency period, actors' interests were actively negotiated. The ministry of education tolerated for a while the cohabitation of teaching programs from different educational systems and afterwards allowed different types of schools to propose a wide range of diversified programs inside the same educational system. This conciliatory spirit persisted till 2007 when planners were struggling to satisfy donors' exigencies in order to join the "Fast Track Initiative". But, the radical changes induced by the extension of free basic education on secondary schools raised internal controversial debate. Teachers and parents from the elite started interpreting some measures taken in order to reduce the cost of education as a sort of promotion of mediocrity. These included the fixation of the repetition rate, the reduction of the number of courses to be taught in primary and secondary schools, the specialization of teachers, etc. When planners faced highly conflicting interests, they behaved as in action theory. They selected their option first and legitimized it through symbolic participative planning.

With regard to financial uncertainty, key findings show that during the emergency period, planners depended totally on external aid but yet did not face challenging exigencies. For all actors, what mattered was to see the educational system recovering from the consequence of the genocide. But from 1998 to 2007, educational plans were mainly designed for external legitimacy in order to increase credibility in the face of funders. International targets on education for all were de facto adopted as national choices in order to facilitate the endorsement of plans by donors. Since 
2008, planners shifted from "outsider" towards an "insider" planning perspective. Projections of future courses of actions were more realistic and aligned to available resources.

In sum, our findings show that planners behave differently in the face of different types of uncertainties: when environmental uncertainty is high as it was the case during the emergency period, planners act without clear predefined goals. When they face divergent internal interests, they either behave as negotiators aiming at reaching a consensual choice or decide first and, legitimize their choice afterwards. When financial uncertainty is more biding, they rely on rational planning to increase external legitimacy and credibility. With regard to educational planning in Rwanda, this trend was dominant from 1998 to 2007. But, once they have secured needed financial resources, they define realistic targets that could be achieved in due time by using available resources, as it happened to be from 2008 to 2015. In light with these results, we consider that existing theories in planning should not be considered as opposed conceptions of the act of planning, but rather as alternative strategies adopted by planners in the face of different types of uncertainties.

\section{References}

1. Andrews, K, L.1971. The concept of corporate strategy. Home wood: Dow Jones-Irwin.

2. Ansoff, H., I.1965. Corporative strategy: An analytic approach to business policy for growth and expansion. New York: McGrawHill.

3. Braybrooke, D., \& Lindbloom, C., E .1963. A strategy of decision. New York: Free Press.

4. Brunsson, N. 1985. The irrational organization: Irrationality as a basis for organization action and change. Chichester: Wiley.

5. Brunsson, N .1982. The irrationality of action and action rationality: decision, ideologies and organizational actions. Journal of management studies, 19(1), 29-44.

6. Dawson, P .1997. "In at the deep and: conducting processual research on organization Change". Scandinavian journal of management 13: 389-405.

7. Fredrickson, J., W .1984. The comprehensiveness of strategic decision processes:

8. Extensions, observations, futures directions. Academy of management journal, 27(3), 445-466.

9. Fredrickson, J., W, \& Iaquinto, A., L .1989. Inertia and creeping rationality in strategic decision processes. Academy of management journal, 32(3), 516-542.

10. Fredrickson, J., W, \& Mitchell, J., R .1984. Strategic decision processes: comprehensiveness and performance in a industry with an unstable environment. Academy of management journal, 27(2), 399-423.

11. Haddad, w. D., \& Demisky, T .1995. Le processus de planification et de formulation des politiques d'éducation: théorie et pratiques. Paris: UNESCO. 
12. Innes, J., E .1995. Planning theory's emerging paradigm: Communicative action and interactive practice. Journal of American planning association, 14(3), 128-135

13. Innes, J., E .1996. Planning through consensus building. A new view of the comprehensive planning ideal. Journal of American planning association, 62(4), 469-472.

14. Innes, J., E .1998. Information in communicative planning. Journal of American planning association, 64(1), 52-63.

15. Innes, J., E , \& Booher, D., E .1999. Consensus building as role playing and bricolage. Toward a theory of collaborative planning. Journal of American planning association, 65(1), 9-26.

16. Kamuzinzi, K .2007. Confrontation de sept modèles explicatifs des visées de la planification en éducation. Élaboration du plan d'éducation pour tous au Rwanda : étude de cas. Thèse de doctorat : Université catholique de Louvain, Belgique.

17. Kamuzinzi, M, M., Bonami, M., Deketele, J, M. 2009a. Modèle d'analyse des conceptions et des pratiques de planification. -Revue française de gestion, 35 (195), p.55-83.

18. Kamuzinzi, M., Deketele, J, M,. Bonami, M .2009b. Les visées de l'action de planification en éducation, Revue française de Pédagogie, 167, p. 85-100.

19. Kaplan, M., A .1976. Means/ends rationality. Ethics, 87(1), 60-65.

20. Learned, E., P, Christensen, C., R, Andrews K, L., \& Guth, W., D 1965. Business policy: Texts ands case. Homewood, IL: Irwin.

21. Lindbloom, C., E .1959. The science of muddling through. Public administration review, 19, 79-88.

22. Lindbloom, C., E .1968. The policy-making process. Englewood, NJ: Prentice-Hall.

23. Llewellyn, S., \& Tappin, E .2003. Strategy in the public sector: Management in the wilderness. Journal of management studies, 40(4), 955-982.

24. McCaskey, M.1974. A contingency approach to planning: Planning with goals and planning without goals. Academy of management journal, 17(2), 281-291.

25. Ministry of Education. 1998. Recovery and Development Education Plan (1998-2000). Kigali: Mineduc

26. Ministry of Education .2003a. Educational plan for all 2003-2015. Kigali: Mineduc

27. Ministry of Education. 2003b. Education Sector Strategic Plan 2003-2008. Kigali: Mineduc

28. Ministry of Education. 2007. Education Sector Strategic Plan 20072011. Kigali: Mineduc

29. Ministry of Education. 2008. Education Sector Strategic Plan 20082012. Kigali: Mineduc

30. Ministry of Education .2010. Education Sector Strategic Plan 20102015. Kigali: Mineduc

31. Mintzberg, H .1990. The design School: Reconsidering the basic premises of strategic Management. Strategic management journal, 11(3), 171-195. 
32. Mintzberg, H .1994. Grandeur et décadence de la planification stratégique. Paris: Dunod.

33. Mintzberg, H., \& Waters, J., A .1982. Tracking strategy in an entrepreneurial firm. Academy of management journal, 25(3), 465499.

34. Orton, J., D .1997. "From inductive to iterative grounded theory: Zipping the gap between process theory and process data". Scandinavian journal of management, 13: 419-438.

35. Pettigrew, A., M .1997. "What is processual analysis". Scandinavian journal of management, 13:337-348.

36. Pfeffer, J., \& Salancik, G., R. 2003. The External Control of Organizations: A Resource Dependence Perspective. New York: Stanford University Press $\left(19781^{\text {st }} \mathrm{ed}\right.$.)

37. Polkinghorne, D., E .1988. Narrative knowing and the human sciences. Albany: State University of New York Press.

38. Quinn, J., B .1982. Managing strategies incrementally. Omega, 10(6), 613-627.

39. Quinn, J., B .1980. Strategy for change: Logical Incrementalism. Irwin: Home wood.

40. Ropo, A., Erickson, P., \& Hunt, J., G .1997."Reflection on conducting processual research on management and organizations". Scandinavian journal of management, 13:331-333.

41. Sotarauta, M .1998. Teaching a Futures-Seeking Communicative Policy Process. American Behavioral Scientist, 42(3), 449461

42. Simon, A., H. 1955. A behavioral model of rational choice. The quarterly journal of Economics, 69(1), 99-118.

43. Starbuck, W., H. 1983. Organizations as action generators. American sociological review, 48, 91-102.

44. Steiner, G., A .1969. Strategic planning: What every manager must now. New York: Free Press.

45. Stone, M. M., \& Brush, C., G .1996. Planning in ambiguous contexts: The dilemma of meeting needs for commitment and demands for legitimacy. Strategic management journal, 17(8), 633-652.

46. Throgmorton, J., A .1996. Planning as persuasive storytelling: the rhetorical construction of Chicago's electric future. Chicago: University of Chicago Press.

47. UNESCO .1983a. Mise en œuvre du plan d'éducation. Paris: UNESCO.

48. UNESCO .1983b. Les projets comme moyens d'exécution des plans d'éducation. Paris: UNESCO.

49. UNESCO .1983c. L'affectation des ressources à l'exécution du plan d'éducation. Paris : UNESCO.

50. UNESCO .1983d. L'exécution du plan d'éducation et processus budgétaire. Paris: UNESCO.

51. UNESCO .1983e. Suivi et évaluation d'un plan d'éducation. Paris: UNESCO.

52. UNESCO .1990. Déclaration mondiale sur l'éducation pour tous. Paris: UNESCO. 
53. UNESCO .2000. Cadre d'action de Dakar sur l'éducation pour tous. Paris: UNESCO.

54. Willson, R .2001. Planning theory in our own backyard Communicative action in academic governance. Journal of Planning Education and Research, 22(3), 297-307.

55. Willson, R. W., Payne, M., \& Smith, E .2003. Does discussion enhance rationality? A report from transportation planning practice. Journal of the American Planning Association, 69(4), 354-367. 